\title{
Serous pigment epithelial detachment in age-related macular degeneration: comparison of different treatments
}

A Lommatzsch, B Heimes, M Gutfleisch, G Spital, $M$ Zeimer and D Pauleikhoff

\begin{abstract}
Aims To investigate the therapeutic effects of different treatments on serous pigment epithelium detachment (PED) in age-related macular degeneration (AMD).

Methods A total of 328 patients suffering from serous PED in AMD were retrospectively analysed. We treated only patients with documented visual deterioration: 86 patients with bevacizumab, 128 with ranibizumab, 60 with pegaptanib, and 54 with photodynamic therapy (PDT) combined with intravitreal triamcinolone acetonide (IVTA). Bestcorrected vision was determined in the logarithm of the minimal angle of resolution (logMAR). We also analysed morphological findings such as full foveal thickness by optical coherence tomography (OCT), manually calculated height of PED as measured by OCT, and fluorescence angiography.

Results The mean follow-up was 42.4 weeks. The best-corrected visual acuity of 0.78 logMAR before treatment could be improved by about $0.066 \log$ MAR after treatment. Retinal thickness decreased in all patients with PED, in the mean by about $64.06 \mu \mathrm{m}$, and the mean value of the manually calculated height decreased by about 0.98 units. All functional and morphological results proved to be significantly better after injection of ranibizumab and bevacizumab than after pegaptanib and the combined treatment with PDT and IVTA. In all, 41 (12.5\%) of our patients developed a tear of the retinal pigment epithelium (RPE). Conclusion The therapeutic results were significantly better in patients treated with
\end{abstract}

bevacizumab and ranibizumab than in those treated with pegaptanib or with a combination of PDT and IVTA. Even with treatment, tears of the RPE or only a partial flattening of the PED always indicated a worse prognosis in eyes with exudative AMD than in eyes with classic choroidal neovascularization.

Eye (2009) 23, 2163-2168; doi:10.1038/eye.2008.425; published online 6 February 2009

Keywords: age-related macular degeneration; retinal pigment epithelium detachment; photodynamic therapy; ranibizumab; bevacizumab; pegaptanib

\section{Introduction}

Age-related macular degeneration (AMD) is one of the main causes of blindness in highly civilized countries. Demographic development and increasing life expectancy will increase this problem in the future. In particular, the development of exudative AMD is responsible for this situation. ${ }^{1-4}$

Modern diagnostic procedures can distinguish among the subgroups of AMD. ${ }^{5,6}$ Around $10 \%$ of all patients present with serous pigment epithelial detachment (PED). The reasons for this are both a mostly marginally situated occult choroidal neovascularization (CNV) and a more centrally situated retinal angiomatous proliferation (RAP). The natural course of disease in this subgroup of AMD is characterized by a slow deterioration in best-corrected visual acuity (BCVA). Over time, more and more atrophic changes develop and ultimately end in an atrophic and fibrotic
Department of

Ophthalmology, St Francis Hospital Muenster, Münster, Germany

Correspondence:

A Lommatzsch, Department of Ophthalmology, St Francis Hospital Muenster,

Hohenzollernring

74,Münster

48145,

Germany

Tel: + 492519330831 ;

Fax: + 492519330819

E-mail:

Albrecht.lommatzsch@ web.de

Received: 3 October 2008 Accepted: 16 December 2008

Published online: 6 February 2009 
disciform scar. This process can be accelerated by ruptures in the retinal pigment epithelium (RPE) layer and by subretinal haemorrhages. ${ }^{7-13}$ Previously used therapeutic strategies such as photocoagulation or photodynamic therapy (PDT) have produced only unsatisfactory results. ${ }^{13-17}$

The reasons for this include both the development of PED and CNV recurrences. Furthermore, treatment could no longer be carried out and thus the development of a central disciform scar could not be avoided.

A combined therapy with PDT and intravitreal injections of triamcinolone acetonide (IVTA) (4 or $25 \mathrm{mg}$ ) has been effective in the treatment of several kinds of AMD. Even if the course of the disease in terms of vision could not be changed significantly, the number of required PDT treatments could be reduced. ${ }^{18,19}$ In addition, the effectiveness of intravitreously injected VEGF inhibitors has been analysed in clinical studies. ${ }^{20-23}$ However, the results of all the different therapeutic procedures have not been compared up to now. Therefore, the aim of this study was to evaluate the data of 328 patients suffering from exudative AMD with serous PED who received different treatment procedures.

\section{Patients and methods}

Between January 2003 and August 2007, 328 patients (224 female, 104 male) with exudative AMD and associated serous PED were treated. The mean age was 77.7 years, the minimal follow-up period 18 weeks, and the mean period 42.4 weeks. The serous PED originated as a result of occult CNV or RAP. None of the patients had received prior eye treatment. The indication for the beginning of treatment was documented disease progression with further visual loss. BCVA was calculated by using the logarithm of the minimal angle of resolution (logMAR). We performed fluorescence angiography (FLA) and indocyanin green angiography (ICG-A) in all patients before beginning treatment. In addition, we used optical coherence tomography (OCT) both before and 6 weeks after the last treatment in each patient. We chose the programs 'fast macular' and the 6-mm crosshair section. Retinal thickness was analysed and the height of PED was measured manually on the monitor. A total of 54 patients received combined therapy with PDT and IVTA. PDT was performed by illuminating the angiographically localized area of neovascularization in accordance with the guidelines of accepted PDT studies. ${ }^{24,25}$ After PDT, we intravitreously injected $4 \mathrm{mg}$ of TA. Later on, 86 patients exclusively received injections with $1.25 \mathrm{mg}$ bevacizumab (Avastin ${ }^{\circledR}$ ), 128 with $0.5 \mathrm{mg}$ ranibizumab (Lucentis ${ }^{\circledR}$ ), and 60 patients with $0.3 \mathrm{mg}$ pegaptanib (Macugen ${ }^{\circledR}$ ).
We administered the drug at intervals of 4 weeks (ranibizumab) and 6 weeks (pegaptanib/bevacizumab).

Follow-up examinations were performed every 4-6 weeks after the last injection and 12 weeks after PDT. Additional treatment was given only in patients with permanent or newly developed leakage. All injections were performed following the accepted guidelines of the German Ophthalmologic Society (Deutsche Ophthalmologische Gesellschaft, DOG). ${ }^{26}$

The statistical calculations were based on the following features: BCVA, changes in the height of PED, and changes in the central retinal thickness.

The frequency of developing RPE tears was registered in all treatment groups. The statistical analysis comprised mean values, median, and standard deviation with confidence intervals (CIs). The regression of visual changes was determined by using regression analysis and correlating non-normally distributed data by means of the Spearman correlation coefficient. The differences in the results between the various treatment groups were compared by means of the Mann-Whitney $U$-test or the Wilcoxon test. We used the program Access/Windows 2003 and Medcalc version 9.6.4.0 and SAS version 9.1 for the statistical calculations.

\section{Results}

The treatments were tolerated well by all of our patients. We did not observe any severe complications such as an increase in intraocular pressure; in particular, no endophthalmitis occurred.

Out of our 328 patients, the data were calculated from the following groups:

1. 54 patients who received combined treatment with PDT and IVTA,

2. 86 patients who received bevacizumab,

3. 128 patients who received ranibizumab,

4. 60 patients who received pegaptanib.

The mean baseline VA was 0.78 (95\% CI 0.75-0.81). The mean difference in VA at first control after treatment as compared with baseline vision was -0.066 (95\% CI -0.10 to -0.03$)$. There was no significant difference between these four treatment modalities at baseline. As shown in Figure 1, there was a significant difference in visual gain between the treatment groups, especially between bevacizumab and pegaptanib $(P=0.025)$, ranibizumab and pegaptanib $(P=0.004)$, and between pegaptanib and PTD with IVTA $(P=0.03)$. Regarding the subgroups as determined by FLA, the mean increase in patients with PED and occult CNV was $0.06 \log$ MAR $(95 \% \mathrm{CI}-0.11$ to -0.02) and in those with serous PED associated with RAP 0.078 (95\% -0.15 to -0.01$)$. This difference was not statistically significant (Mann-Whitney $U$-test $P=0.71$ ). 


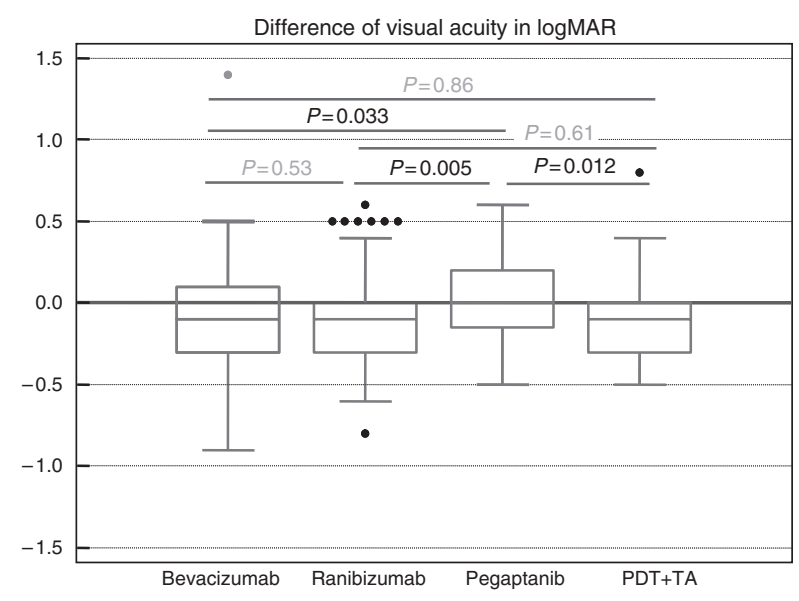

Figure 1 Difference in visual acuity for each treatment. The $P$-value is noted for the Mann-Whitney $U$-test.

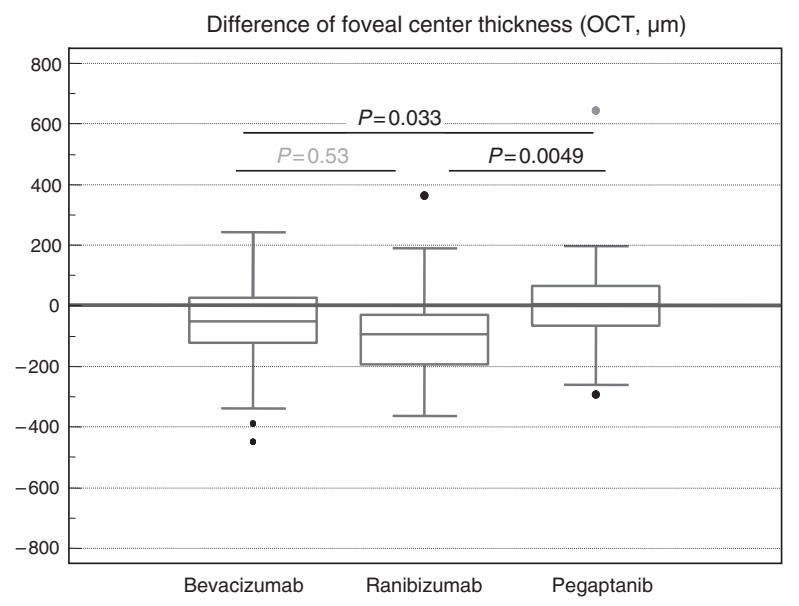

Figure 2 Difference in foveal centre thickness in OCT in $\mu \mathrm{m}$. In the three groups that received injection therapy, there was a significant difference between all groups.

In addition, the difference in morphological characteristics between the different treatment groups was statistically significant.

Central retinal thickness decreased significantly after ranibizumab and bevacizumab $(P<0.0001 / P=0.0002)$, whereas after pegaptanib no significant change could be observed ( $P=0.89$, Figure 2). The therapeutic effect was more favourable regarding retinal thickness in patients with serous PED associated with RAP lesions (mean difference $=-86.5, P<0.001$ ) than in those with PED and occult CNV (mean difference $=-55.2, P<0.001$ ). The maximum height of PED calculated on the OCT images decreased in all treatment groups. PED height decreased less in patients treated with pegaptanib and bevacizumab than in those with ranibizumab, which was statistically significant in comparison with bevacizumab $(P=0.023$, Figure 3). However, for the morphological

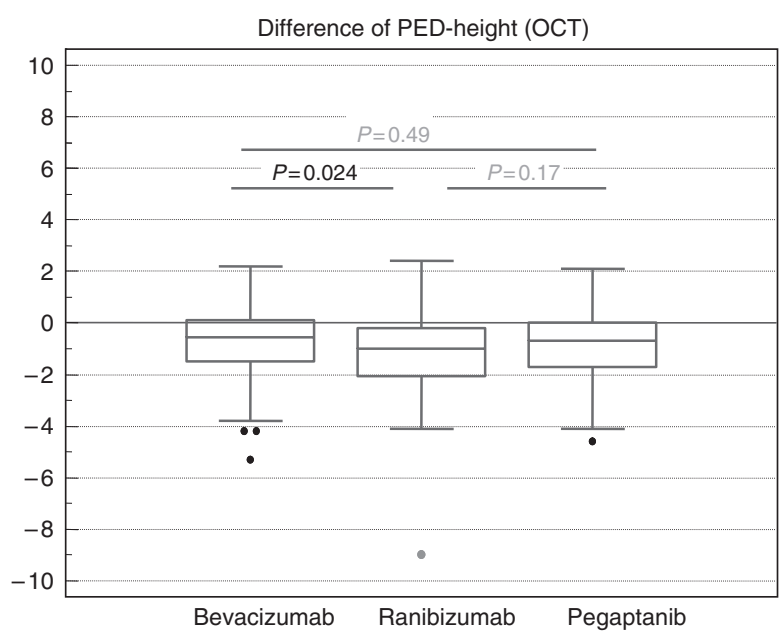

Figure 3 Decrease of height of PED with a significant difference between bevacizumab and ranibizumab.

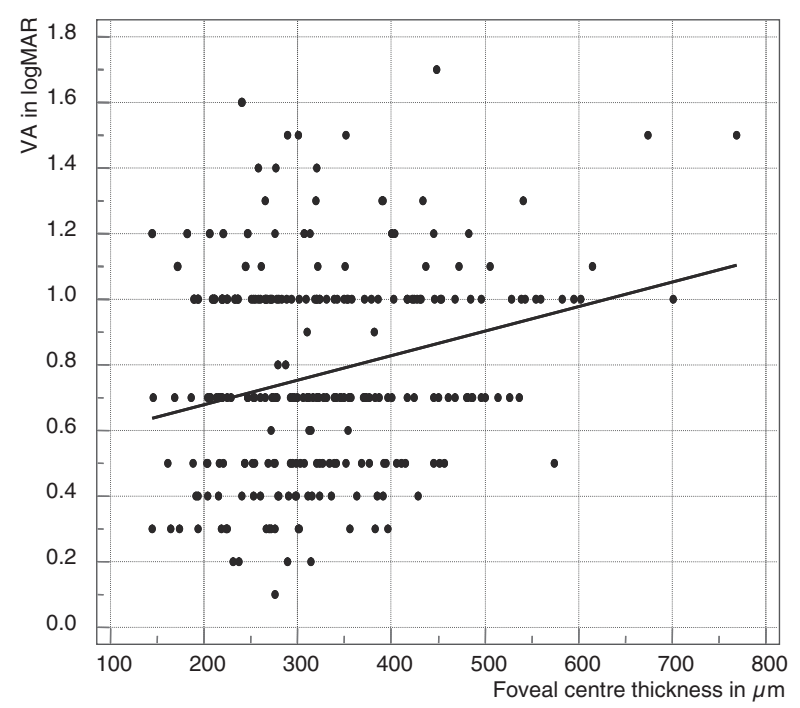

Figure 4 Correlation between foveal centre thickness in $\mu \mathrm{m}$ and visual acuity in $\log$ MAR at baseline. Spearman correlation coefficient is $0.21(P=0.0008)$.

subgroups as determined by FLA, no significant difference could be observed between RAP and occult CNV.

In all groups, there was a significant correlation between the development of VA and retinal thickness; Spearman correlation coefficient before treatment was $0.21(P=0.0008)$ and at 12 weeks after treatment $0.33(P<0.0001)$ (Figure 4$)$. Consequently, the reduction in central retinal thickness produced an improvement in vision.

During the follow-up period, 41 patients (12.5\%) developed a tear of the RPE; in patients who were treated with VEGF inhibitors, the frequency was 9.9\% (bevacizumab $13(15.1 \%)$ patients, ranibizumab 11 (8.6\%) 
patients, and pegaptanib $3(5 \%)$ patients), and after combined treatment with PDT and IVTA, 14 (25.9\%) patients developed PE tears $\left(\chi^{2} P=0.0018\right.$, Figure 5).

\section{Discussion}

Occult CNV or RAP associated with serous PED has been established as a specific entity in patients with exudative

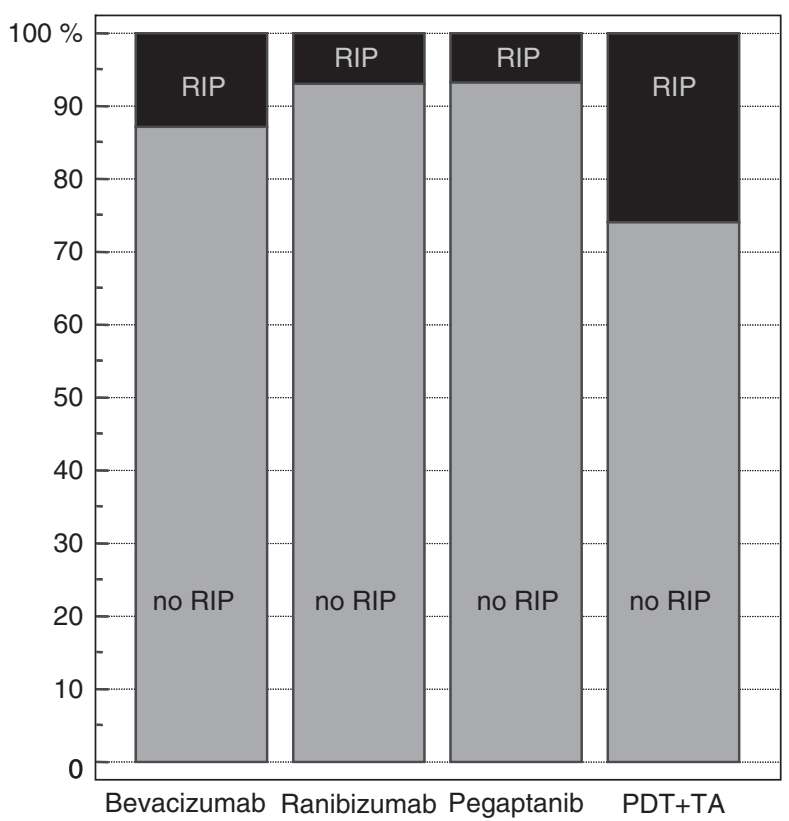

Figure 5 Frequency of tears of RPE in different treatment groups ( $\chi^{2}$ test $P=0.0025$ ).
AMD. ${ }^{7,8,11,27}$ In addition, the second eye is frequently involved and a bilateral disciform macular scar also often develops as disease progresses. Acute visual loss can be caused by tears of the RPE layer, especially in combination with massive subretinal haemorrhages. ${ }^{2,11-13,28,29}$

Using ICG-A, different kinds of neovascularization could be identified that can be regarded as being responsible for serous PED. Occult CNV situated mostly at the margin can often be distinguished from centrally localized CNV on a RAP lesion. ${ }^{27,30,31}$ It has been shown that even with early laserphotocoagulation treatment or PDT, it is not possible to stabilize disease or slow down disease progression. ${ }^{14,15,17,32}$ The reasons for these treatment failures were untreatable recurrences or the development of RPE tears.

However, as a combined treatment with PDT and IVTA has been introduced, the results have improved.

Specifically, the development of recurrences and the number of treatments could be reduced. Only some authors have described post-therapeutic visual loss associated with this treatment modality, whereas most authors report a higher rate of stabilization of both BCVA and morphological changes. ${ }^{18,19,33}$

We can confirm these results of significant stabilization of vision during a follow-up period of 24 weeks.

Nevertheless, the rate of RPE ruptures still remained high.

These RPE tears and haemorrhages were most often localized outside the fovea and resulted in minor loss of vision. However, the uncertain long-term prognosis in these patients and the high rate of possible IVTA complications (cataract, glaucoma) prompted the search
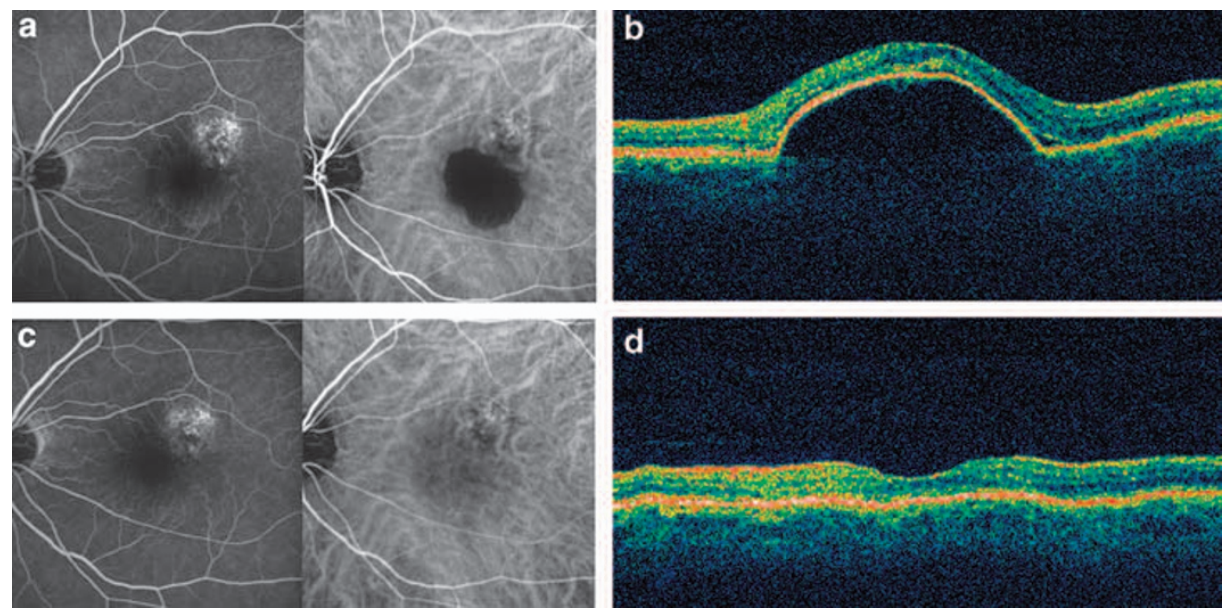

Figure 6 A 68-year-old man was referred for decreased BCVA in the right eye. Examination revealed an elevated subfoveal lesion. Pre-ranibizumab imaging (FAG, ICG-A) shows intense hyperfluorescence of the occult lesion zone of leakage of CNV and associated PED (a). The OCT imaging of the macula shows the corresponding PED height; intraretinal and subretinale fluid are visible (b). The same eye 3 months after the upload therapy with ranibizumab. A reduction of the hypofluorescence PED area and the leakage of the occult CNV could be observed (c). The OCT imaging showed an almost complete recovery of PED height (d). 
for different and new kinds of treatments. Indeed, VEGF inhibitors opened new doors in the treatment of exudative AMD. ${ }^{34-36}$ The first encouraging results in the treatment of serous PED were found with pegaptanib, followed by bevacizumab and ranibizumab. ${ }^{37-40}$ However, these initial reports comprised only small numbers of treated patients. In our larger case series, we found a significant stabilization of VA over a period of 24 weeks after treatment. The different drugs used in this study also showed different effects on the morphological characteristics examined. As also shown by other studies, changes in the central thickness of the retina correlate highly with an increase of BCVA. After ranibizumab and bevacizumab treatment, we achieved significantly higher decreases in retinal thickness than with pegaptanib. In addition, the height of PED declined less after pegaptanib than after ranibizumab and bevacizumab (Figure 6). Ranibizumab and bevacizumab are more effective in reducing vascular permeability than pegaptanib, which would explain this.

However, our results were not as optimistic as those published in other clinical studies. ${ }^{22,40}$ A possible reason for that is the generally worse prognosis and the better therapeutical influence for the patients with classic $\mathrm{CNV}$ than for those with CNV without PED. In classic CNV, the intraretinal oedema and subretinal fluid is the major cause for visual decrease. These factors can be effectively reduced by anti-VEGF therapy. In contrast, serous PED patients have intra- and subretinal as well as sub-RPE fluid. As the reason for this fluid accumulation is thought to be, at least in the past, due to changes in the hydroconductivity of Bruch's membrane, the effects of anti-VEGF therapy on fluid reduction in these patients are not that effective.

In some patients, a tear of the RPE developed already some weeks after the intravitreal injection. ${ }^{41-44}$ In our series, we observed this in $12 \%$ of all patients who were treated with VEGF inhibitors. The differences observed between these drugs are not statistically significant because of the relatively small number of cases. The longterm prognosis in these patients has not been defined either, and especially the question of the long-term treatment strategy is still open.

Therefore, we can conclude that PDT with IVTA, ranibizumab, bevacizumab, and pegaptanib can stabilize occult CNV associated with serous PED and RAP associated with PED. Treatment with bevacizumab and ranibizumab produced significantly better morphological and visual results than pegaptanib and fewer complications than PDT with IVTA. However, as only a partial regression can be achieved and RPE tears can generally not be avoided, we must continuously search for more specific, more effective treatment modalities that are associated with fewer side effects.
As serous PED could only be reduced in most patients and because the course of RPE tears with and without further treatment is not known, long-term treatment strategies and prognosis should be defined.

\section{References}

1 Bressler NM. Age-related macular degeneration is the leading cause of blindness. JAMA 2004; 291(15): 1900-1901.

2 Bird AC, Bressler NM, Bressler SB, Chisholm IH, Coscas G, Davis MD et al. An international classification and grading system for age-related maculopathy and age-related macular degeneration. The International ARM Epidemiological Study Group. Surv Ophthalmol 1995; 39(5): 367-374.

3 Bird AC. Pathogenesis of lesions in late age-related macular disease.. J Fr Ophtalmol 2005; 28(9): 984.

4 Holz FG, Pauleikhoff D, Klein R, Bird AC. Pathogenesis of lesions in late age-related macular disease. Am J Ophthalmol 2004; 137(3): 504-510.

5 Shimada H, Kawamura A, Mori R, Yuzawa M. Clinicopathological findings of retinal angiomatous proliferation. Graefes Arch Clin Exp Ophthalmol 2007; 245(2): 295-300.

6 Ahlers C, Michels S, Beckendorf A, Birngruber R, Schmidt-Erfurth U. Three-dimensional imaging of pigment epithelial detachment in age-related macular degeneration using optical coherence tomography, retinal thickness analysis and topographic angiography. Graefes Arch Clin Exp Ophthalmol 2006; 244(10): 1233-1239.

7 Gass JD. Serous retinal pigment epithelial detachment with a notch. A sign of occult choroidal neovascularization. Retina 1984; 4(4): 205-220.

8 Bird AC, Marshall J. Retinal pigment epithelial detachments in the elderly. Trans Ophthalmol Soc UK 1986; 105: 674-682.

9 Bird AC. Doyne Lecture. Pathogenesis of retinal pigment epithelial detachment in the elderly; the relevance of Bruch's membrane change. Eye 1991; 5: 1-12.

10 Lafaut BA, Aisenbrey S, Vanden Broecke C, Krott R, Jonescu-Cuypers $\mathrm{CP}$, Reynders $\mathrm{S}$ et al. Clinicopathological correlation of retinal pigment epithelial tears in exudative age related macular degeneration: pretear, tear, and scarred tear. Br J Ophthalmol 2001; 85(4): 454-460.

11 Pauleikhoff D, Loffert D, Spital G, Radermacher M, Dohrmann J, Lommatzsch A et al. Pigment epithelial detachment in the elderly. Clinical differentiation, natural course and pathogenetic implications. Graefes Arch Clin Exp Ophthalmol 2002; 240(7): 533-538.

12 Cohen SY, Creuzot-Garcher C, Darmon J, Desmettre T, Korobelnik JF, Levrat $\mathrm{F}$ et al. Types of choroidal neovascularisation in newly diagnosed exudative agerelated macular degeneration. Br J Ophthalmol 2007; 91(9): 1173-1176.

13 Zayit-Soudry S, Moroz I, Loewenstein A. Retinal pigment epithelial detachment. Surv Ophthalmol 2007; 52(3): 227-243.

14 Gelisken F, Inhoffen W, Partsch M, Schneider U, Kreissig I. Retinal pigment epithelial tear after photodynamic therapy for choroidal neovascularization. Am J Ophthalmol 2001; 131(4): 518-520.

15 Pece A, Isola V, Vadala M, Calori G. Photodynamic therapy with verteporfin for choroidal neovascularization associated 
with retinal pigment epithelial detachment in age-related macular degeneration. Retina 2007; 27(3): 342-348.

16 Bird AC. Treatment of pigment epithelial detachments in the elderly. Trans Ophthalmol Soc NZ 1983; 35: 73-75.

17 Goldstein M, Heilweil G, Barak A, Loewenstein A. Retinal pigment epithelial tear following photodynamic therapy for choroidal neovascularization secondary to AMD. Eye 2005; 19(12): 1315-1324.

18 Axer-Siegel R, Ehrlich R, Avisar I, Kramer M, Rosenblatt I, Priel $\mathrm{E}$ et al. Combined photodynamic therapy and intravitreal triamcinolone acetonide injection for neovascular age-related macular degeneration with pigment epithelium detachment. Ophthalmic Surg Lasers Imaging 2006; 37(6): 455-461.

19 Krebs I, Binder S, Stolba U. A new treatment regimen in combined intravitreal injection of triamcinolone acetonide and photodynamic therapy. Graefes Arch Clin Exp Ophthalmol 2006; 244(7): 863-867.

20 Bashshur ZF, Haddad ZA, Schakal A, Jaafar RF, Saab M, Noureddin $\mathrm{BN}$. Intravitreal bevacizumab for treatment of neovascular age-related macular degeneration: a one-year prospective study. Am J Ophthalmol 2008; 145(2): 249-256.

21 Ladas ID, Kotsolis AI, Papakostas TD, Rouvas AA, Karagiannis DA, Vergados I. Intravitreal bevacizumab combined with photodynamic therapy for the treatment of occult choroidal neovascularization associated with serous pigment epithelium detachment in age-related macular degeneration. Retina 2007; 27(7): 891-896.

22 Lai TY, Chan WM, Liu DT, Lam DS. Ranibizumab for retinal angiomatous proliferation in neovascular age-related macular degeneration. Graefes Arch Clin Exp Ophthalmol 2007; 245(12): 1877-1880

23 Weinberger AW, Thiel M, Mohammadi B, Theofylaktopoulos I, Thumann G, Walter P. Retinal pigment epithelium tears after intravitreal bevacizumab in pigment epithelium detachment. Am J Ophthalmol 2007; 144(2): 294-296.

24 Photodynamic therapy of subfoveal choroidal neovascularization in age-related macular degeneration with verteporfin: one-year results of 2 randomized clinical trials - TAP report. Treatment of age-related macular degeneration with photodynamic therapy (TAP) Study Group. Arch Ophthalmol 1999; 117(10): 1329-1345.

25 Verteporfin In Photodynamic Therapy Study Group. Verteporfin therapy of subfoveal choroidal neovascularization in age-related macular degeneration: two-year results of a randomized clinical trial including lesions with occult with no classic choroidal neovascularization - verteporfin in photodynamic therapy report 2. Am J Ophthalmol 2001; 131(5): 541-560.

26 Jaissle GB, Szurman P, Bartz-Schmidt KU. Recommendation for the implementation of intravitreal injections - statement of the German Retina Society, the German Society of Ophthalmology (DOG) and the German Professional Association of Ophthalmologists (BVA). Klin Monatsbl Augenheilkd 2005; 222(5): 390-395.

27 Yannuzzi LA, Negrao S, lida T, Carvalho C, RodriguezColeman H, Slakter J et al. Retinal angiomatous proliferation in age-related macular degeneration. Retina 2001; 21(5): 416-434.

28 Spital G, Brumm G, Radermacher M, Muller C, Lommatzsch A, Pauleikhoff D. Volume determination of pigment epithelium detachment in AMD by laser scanning tomography. Ophthalmologe 2000; 97(3): 173-180.
29 Lee WK, Park YH, Lee PY. Neovascularization associated with large retinal pigment epithelial detachment in elderly Korean patients: subdivision according to indocyanine green angiographic features. Jpn J Ophthalmol 2007; 51(3): 216-223.

30 Sallet G, Lafaut BA, De Laey JJ. Indocyanine green angiography and age-related serous pigment epithelial detachment. Graefes Arch Clin Exp Ophthalmol 1996; 234(1): 25-33.

31 Truong SN, Alam S, Zawadzki RJ, Choi SS, Telander DG, Park SS et al. High resolution Fourier-domain optical coherence tomography of retinal angiomatous proliferation. Retina 2007; 27(7): 915-925.

32 Gomez-Ulla F, Abraldes MJ, Fernandez M, Olmedo M. Successful treatment of retinal angiomatous proliferation by photodynamic therapy. Optom Vis Sci 2006; 83(8): 546-549.

33 Freund KB, Klais CM, Eandi CM, Ober MD, Goldberg DE, Sorenson JA et al. Sequenced combined intravitreal triamcinolone and indocyanine green angiography-guided photodynamic therapy for retinal angiomatous proliferation. Arch Ophthalmol 2006; 124(4): 487-492.

34 Fung AE, Rosenfeld PJ, Reichel E. The International Intravitreal Bevacizumab Safety Survey: using the internet to assess drug safety worldwide. Br J Ophthalmol 2006; 90(11): 1344-1349.

35 Gragoudas ES, Adamis AP, Cunningham Jr ET, Feinsod M, Guyer DR. Pegaptanib for neovascular age-related macular degeneration. N Engl J Med 2004; 351(27): 2805-2816.

36 Chakravarthy U, Adamis AP, Cunningham Jr ET, Goldbaum M, Guyer DR, Katz B et al. Year 2 efficacy results of 2 randomized controlled clinical trials of pegaptanib for neovascular age-related macular degeneration. Ophthalmology 2006; 113(9): 1508 e1501-e1525.

37 Costagliola C, Romano MR, dell'Omo R, Cipollone U, Polisena P. Intravitreal bevacizumab for the treatment of retinal angiomatous proliferation. Am J Ophthalmol 2007; 144(3): 449-451.

38 Gelisken F, Ziemssen F, Voelker M, Bartz-Schmidt KU, Inhoffen W. Retinal pigment epithelial tears after single administration of intravitreal bevacizumab for neovascular age-related macular degeneration. Eye 2008 [e-pub ahead of print].

39 Joeres S, Heussen FM, Treziak T, Bopp S, Joussen AM. Bevacizumab (Avastin) treatment in patients with retinal angiomatous proliferation. Graefes Arch Clin Exp Ophthalmol 2007; 245(11): 1597-1602.

40 Meyerle CB, Freund KB, Iturralde D, Spaide RF, Sorenson JA, Slakter JS et al. Intravitreal bevacizumab (Avastin) for retinal angiomatous proliferation. Retina 2007; 27(4): 451-457.

41 Chang LK, Flaxel CJ, Lauer AK, Sarraf D. RPE tears after pegaptanib treatment in age-related macular degeneration. Retina 2007; 27(7): 857-863.

42 Dhalla MS, Blinder KJ, Tewari A, Hariprasad SM, Apte RS. Retinal pigment epithelial tear following intravitreal pegaptanib sodium. Am J Ophthalmol 2006; 141(4): 752-754.

43 Kook D, Wolf A, Neubauer AS, Haritoglou C, Priglinger SG, Kampik A et al. Retinal pigment epithelial tears after intravitreal injection of bevacizumab for AMD. Frequency and progress. Ophthalmologe 2008; 105(2): 158-164.

44 Spandau UH, Jonas JB. Retinal pigment epithelium tear after intravitreal bevacizumab for exudative age-related macular degeneration. Am J Ophthalmol 2006; 142(6): 1068-1070. 